\title{
Study of Recrystallization Kinetics of 1565ch Aluminum Alloy during hot deformation
}

\author{
Vasiliy Yashin ${ }^{1,2}$, Alexander Drits $^{2}$, Evgenii Aryshenskii ${ }^{*}$, Ilya Latushkin $^{1,2}$ and Ekaterina Chitnaeva ${ }^{1,2}$ \\ ${ }^{1}$ Samara National Research University, 443086 Samara, Russia \\ ${ }^{2}$ JSC ”Arconic SMZ”, 443051 Samara, Russia
}

Study is funded by a grant of the Russian Science Foundation, project 18-79-10099.

\begin{abstract}
The present study addresses recrystallization process in Al-Mg-Mn-Zn-Zr system alloy samples. The samples are collected from cast ingot, produced by casting to industrial DC mold, and homogenized based on standard industrial practice. After that the samples were rolled with different hot rolling schedules. Rolled samples were annealed at different temperatures and their resultant microstructure was examined using optical microscope. During the study new grains nuclei generation rate and their growth rate were determined, analytical records, describing recrystallization kinetics, were obtained, main differences, specific to this alloy recrystallization in $350{ }^{\circ} \mathrm{C}-450{ }^{\circ} \mathrm{C}$ temperature range, were identified.
\end{abstract}

\section{Introduction}

Multiple studies address recrystallization process [1-9], processes, occurring during cold worked metal annealing [3], as well as processes occurring during hot deformation of preliminary worked over structure [1013] are well studied and described in detail, however, only few studies deal with recrystallization during early stages of hot deformation $[1,14,15]$. They use diverging data, producing invalid results, if applied in calculations of hot rolling initial passes. The causes stem from the following features specific to hot rolling initial passes: low strain level (ranging from 0.04 to 0.35 , whereas researches mainly focus on the strain level, exceeding 0.4 ), low strain rate (ranging from 1 to $10 \mathrm{~s}^{-1}$ ), high temperature $\left(400-500 \quad{ }^{\circ} \mathrm{C}\right)$ and cast structure, characterized by large interdendritic distance (about 200 $\mathrm{mcm}$ ).

However, structure evolution process study is invalid without understanding of structural modifications, occurring during the very early deformation phase. There is a trend to slab thickness increase, hence deformation non-uniformity will build up during multi-pass rolling, initial $5 \div 10$ passes may involve full ingot surface recrystallization and completely intact as-cast structure in the ingot midsection. In this case the produced workpiece will be characterized not only by high mechanical properties anisotropy, it will demonstrate high scrap potential, eg., laminations and cracks, this is specifically true for hard alloys. It is difficult to predict the structure during hot rolling with high deformation centre, as the following multiple factors shall be accounted for: workpiece heating during plastic deformation and cooling down due to roll contact, strain level and rate heterogeneity, with max values in near-contact zone and min values in the slab axis, inter-deformation interval time varying from pass to pass and along the specimen length. The above necessitates recrystallization processes describing as mathematical model, which can be applied as a function for rolling process computation using FEM mode.

Recrystallization of magnesium rich aluminum alloy with transition elements addition presents special interest. Thus, zirconium, added to aluminum alloys for as-cast structure refinement [12 - 17], as well as for product strength improvement, is widely applied. Strengthening is achieved due to two factors: dispersion strengthening and structural strengthening. Heating temperature and hot deformation schedules control enable managing precipitation of fine particles (sized about $10 \mathrm{~nm}$ ), coherent with aluminum matrix [18, 19], from the solid solution. Fine particles number control, combined with $\mathrm{Mg} 2 \mathrm{Al}$ and $\mathrm{Al}(\mathrm{MnFe})$ type coarse intermetallic particles, occurring in this alloy group and functioning as new grains nuclei $[20,21]$, can be the key to structure refinement during recrystallization. Such concept was efficiently deployed to design a new alloy $1565 \mathrm{ch}$ with average amount of transition elements [22]. $1565 \mathrm{ch}$ alloy belongs to weldable alloys of $\mathrm{Al}-\mathrm{Mg}$ system and can be described as versatile material, demonstrating optimal combination of strength, plasticity and special features, dictated by its application field. Having plasticity characteristics, comparable with 1550 and 5083 alloys, this alloy is $20-30 \%$ superior in strength. $1565 \mathrm{ch}$ alloy is recommended for manufacturing of freight cars and tankers, carrying bulk or hazardous products, as well as articles and machinery, operating at cryogenic temperatures (down to minus 196 $\left.{ }^{\circ} \mathrm{C}\right)$. Compared to conventional alloys, the innovative

* Corresponding author: ar-evgenii@ya.ru 
$1565 \mathrm{ch}$ alloy has the optimal combination of mechanical properties, demonstrated both in low and high temperature conditions. Due to its improved plasticity, as compared to 1560 and 1561 alloys, it is more appropriate for body structures fabrication.

This study addresses recrystallization kinetics in $1565 \mathrm{ch}$ samples, having initial as-cast structure, and processed with the above range of temperature-rate parameters.

\section{Research methodology}

10x40x300 samples, collected from 1565ch (for chemical composition refer to Table 1) DC cast, homogenized slab ( $8 \mathrm{~h}$ homogenization with $485-500{ }^{\circ} \mathrm{C}$ metal temperature) were used in the experiment, the samples were rolled in the lab mill, following the practices, specified in the Table 2. After rolling completion the samples were immediately transferred to the water tank for structure freezing. Max sample transfer time was $2 \mathrm{~s}$.

Table 1. Test slab chemical composition.

\begin{tabular}{|c|c|c|c|c|c|c|c|c|}
\hline \multirow{2}{*}{$\begin{array}{l}\text { Chemical } \\
\text { element }\end{array}$} & \multicolumn{8}{|c|}{ Composition, \% (weight) } \\
\hline & $\mathrm{Al}$ & $\mathrm{Cu}$ & $\mathrm{Mg}$ & $\mathrm{Mn}$ & $\mathrm{Fe}$ & $\mathrm{Si}$ & $\mathrm{Zn}$ & $\mathrm{Zr}$ \\
\hline $1565 \mathrm{ch}$ & $\begin{array}{l}\mathscr{D} \\
\tilde{D} \\
\tilde{D}\end{array}$ & $\stackrel{\infty}{0}$ & $\stackrel{n}{n}$ & $\hat{\theta}$ & $\frac{1}{0}$ & $\stackrel{\infty}{\circ}$ & $\hat{\sigma}$ & $\overrightarrow{0}$ \\
\hline
\end{tabular}

Table 2. Experiment variables

\begin{tabular}{|c|c|c|c|c|}
\hline Practice No. & $\varepsilon, \operatorname{Ln}(\mathrm{h} 0 / \mathrm{hk})$ & $\dot{\varepsilon}, \mathrm{s}^{-1}$ & $\mathrm{~T}_{\text {def }}{ }^{\circ} \mathrm{C}$ & $\mathrm{Z}$ \\
\hline 1 & 0.34 & 3 & 350 & $6.63 \mathrm{E}+14$ \\
\hline 2 & 0.35 & 8 & 350 & $1.77 \mathrm{E}+15$ \\
\hline 3 & 0.34 & 3 & 450 & $6.88 \mathrm{E}+12$ \\
\hline 4 & 0.34 & 8 & 450 & $1.84 \mathrm{E}+13$ \\
\hline 5 & 0.36 & 3 & 350 & $6.63 \mathrm{E}+14$ \\
\hline 6 & 0.56 & 8 & 350 & $1.77 \mathrm{E}+15$ \\
\hline 7 & 0.36 & 3 & 400 & $5.70 \mathrm{E}+13$ \\
\hline 8 & 0.54 & 8 & 400 & $1.52 \mathrm{E}+14$ \\
\hline 9 & 0.36 & 3 & 450 & $6.88 \mathrm{E}+12$ \\
\hline 10 & 0.54 & 8 & 450 & $1.84 \mathrm{E}+13$ \\
\hline 11 & 0.51 & 3 & 500 & $1.09 \mathrm{E}+12$ \\
\hline
\end{tabular}

Rolled strips were cut into $5 \times 10 \times 10$ samples, which were annealed at $350,400,450{ }^{\circ} \mathrm{C}$ temperature settings with different soaking durations, for heating time reduction annealing was performed in saltpeter, heating rate was $20^{\circ} \mathrm{C} / \mathrm{s}$.

The obtained samples structure was examined using optical metallography methods with 50X magnification. The samples were prepared by electrolytic polishing in fluoroboric electrolyte. Grain size was evaluated using secant method as per GOST 21073.2.

Scanning electron microscope FEI InspectS with back-scatter electron detector (BSED) having $10 \mathrm{~nm}$ image resolution and integrated energy dispersive X-ray micro-analyser EDAX, enabling identifying elements from $B$ to $\mathrm{U}$, was used for particles analysis in 10 fields with $10^{\circ} 000 \mathrm{X}$ magnification. ImageScope software complex was applied for images processing and phases counting.

General post-deformation recrystallization kinetics is described by Avrami equation

$$
\text { Xrex }=1-\exp \left[-0,693\left(t / t_{0,5}\right)^{n}\right]
$$

where $t_{0,5}$ is the time, required to achieve $50 \%$ recrystallization; is current post-deformation soaking time; $n$ is the index with the values ranging from 1 to 2 , depending on the material.

For single-phase materials time $t_{0,5}$, required to recrystallize $50 \%$ of the deformed material volume, is determined by the equation

$$
t_{0,5}=A d_{o}{ }^{r} \varepsilon^{-p} Z^{-q} \exp \left(Q_{\text {rex }} / R T\right)
$$

Here $A, p, q, r$ are material constants; $d_{0}$ is initial grain size; $\varepsilon$ is strain value; $Q_{r e x}$ is recrystallization activation energy; $\mathrm{T}$ is absolute isothermal time; $R$ is gas constant; $Z$ is Zener-Hollomon parameter, dependent on the strain rate $(\dot{\varepsilon})$, temperature $\left(T_{d e f}\right)$ and activation energy of the process, managing strain rate $\left(Q_{d e f}\right)$ :

$$
Z=\dot{\varepsilon} \exp \left(Q_{\text {def }} / R T_{d}\right)
$$

The situation is more complicated for the alloys with phases inclusions. Nano-size dispersoids efficiently retard grain boundaries mobility, hence recrystallization processes, while coarse inclusions (over $1 \mathrm{mcm}$ ) can serve as new recrystallized grains nucleation centres, thus accelerating recrystallization kinetics.

The most rigorous method of recrystallization kinetics study is to study microstructure of the quenched deformed samples with various post-deformation soaking periods. The example of such method application is the study [13], addressing hot rolled alloys AA5182 (Al-4,5\%Mg-0,31\%Mn-0,21\%Fe $)$ and AA5052 (Al-2,5\%Mg-0,07\%Mn-0,17\% Cr-0,27\% Fe) with fully recrystallized initial structure. It demonstrated, that alloy AA5182 static recrystallization was much faster, than in AA5052 alloy. Recrystallization kinetics difference is explained by higher magnesium content (higher level of strain hardening) and smaller initial grains in AA5182 alloy, as well as presence of fine chrome intermetallic particles in AA5052 alloy.

To account for dispersoids contribution in $1565 \mathrm{ch}$ alloy recrystallization kinetics, recrystallization process was divided into two sub-processes, i.e., new grains nucleation and grains growth:

- specific rate of new grains nucleation (per $1 \mathrm{mcm} 2$ area)

$$
\dot{N}=\Delta N /(\Delta \tau \cdot S)
$$

- grain growth rate $\dot{D}=\Delta D / \Delta \tau$

New grains nucleation rate and grains growth rate were determined by metallographic examination of the structure at various soaking time settings, assuming these values are time independent. Grain increment or grain size change were determined for $\mathrm{S}=5.72 \mathrm{~mm}^{2}$ area with growth rate computation, target values were obtained by achieved values division by soaking duration. 
Equation for $1565 \mathrm{ch}$ alloy can be presented in the following form:

$X(\tau)=1-\exp \left(-K(\tau)^{n}\right)$

where $K=\pi \dot{N} \dot{D}^{3}$ and $n=4$;

$\dot{N}=7,1 \cdot 10^{24} \cdot \varepsilon^{0.26} Z^{0.1} \exp \left(-165059 / R T_{\text {rec }}\right)$

$$
\dot{D}=\mu \cdot\left(P_{D^{-}} P_{Z}\right)
$$

where $\mu$ is boundary mobility, dependent on its atomic structure;

$P_{d^{-}}$- migration driving force;

$P_{z}-$ retarding force.

Temperature dependence of the boundary mobility $\mu$ is described by the following equation:

$$
\mu=1,9 \cdot 10^{-7} \exp \left(-85068 / R T_{\text {rec }}\right)
$$

Primary recrystallization driving force $\mathrm{P}_{\mathrm{D}}$ is the decrease of excess volumetric energy, accumulated during plastic deformation. Primarily, it is defined by the difference in dislocation density $\Delta N_{d}$ before and after deformation:

$$
P_{D} \approx k \Delta N_{d} G B^{2}
$$

where $k$ is the factor, considering the nature of dislocations distribution and ranging from 0.1 to $1 ; G$ is shear module, equal to $2.5 \cdot 10^{10} \mathrm{~N} / \mathrm{m}^{2} ; B$ is Burgers vector $0.286 \mathrm{~nm}, \Delta N_{d}$ is a function of strain degree, determined by the following formula [23]:

$$
d N_{d} / d \varepsilon=k_{1}\left(N_{d}+k_{p}(f / r)^{2}\right)^{0.5}-k_{2} N_{d}
$$

where $f$ and $r$ are proeutectoid constituent particles volume fraction and size;

$k_{p}$ is the coefficient, responsible for accumulation of dislocations on proeutectoid constituent particles.

Coefficients $k_{1}, k_{2}$ and $k_{p}$ values were computed by numerical solution of differential equation (9):

$k_{p}=2 \cdot 10^{5}$;

$k_{l}=\left(0.95+0.44 C^{0.5}\right) 10^{8}, \mathrm{~m}^{-1}$;

$k_{2}=7.2-0.75 C^{0.5}$.

For integration of evolution equation (9) initial dislocation density value $N_{d 0}=10^{10} \mathrm{~m}^{-2}$ was applied (such density value is typical for thermally treated castings and alloys, recrystallized after deformation).

Presence of dispersion phases affects boundaries migration retardation. Boundaries migration by dispersion phases is caused by boundaries and overall system energy decrease as a result of dispersion phases location at the boundary.

In case specific number of $N_{d}$ dispersoids is present in the structure $(2 \div 4$ atomic percent [14]) the force, retarding boundaries mobility, will be computed as follows:

$$
P_{Z} \approx 3 f \gamma_{c p} / d
$$

where $f$ - is particles volume fraction, equal to $f=4 \pi \cdot r_{0}^{3} \cdot N_{d} / 3$

$N_{d}$ - is particles count per $1 \mathrm{~m}^{3}$ and size $r_{0}$, calculated using the data from Table 3 .

$\gamma_{b}$ - is inter-grain boundary energy $\approx 0.5 \mathrm{~J} \cdot \mathrm{m}^{-2}[14]$.

Zener was the first to present this relationship. It means, that the larger particles volume fraction is, the smaller the particles are, and the higher $\gamma_{b}$ is, the stronger particles dragging effect is. It is clear, that boundary migration is possible only, if $P_{D}>P_{Z}$.

\section{Research results and discussion}

Prior to testing, the samples were examined using scanning microscope to determine the intermetallic particles number, size and chemical composition; grain microstructure was examined using optical microscope. Figure 1a illustrates cellular-dendritic pattern of the alloy crystallization, microstructure has distinctive dendritic branches. Average grain size is $\sim 200 \mathrm{mcm}$. Additions of 0.67 weight $\% \mathrm{Zn}$ and 0.11 weight $\% \mathrm{Zr}$ do not result in significant change of workpiece as-cast structure as compared to similar alloys of Al-Mg system. Primary intermetallic particles of crystallization origin with the sizes, ranging from $1 \mathrm{mcm}$ to $31 \mathrm{mcm}$ can be observed in the ingots. Energy dispersive X-ray micro-analysis identified $\mathrm{Al} 3 \mathrm{Mg} 2, \mathrm{Al}(\mathrm{Fe}, \mathrm{Mn})$ intermetallic particles and $\mathrm{Mg} 2 \mathrm{Si}$ magnesium silicide, located along grain boundaries. No zirconium or zinc containing additional phases were identified in $1565 \mathrm{ch}$ alloy during microanalysis, thus it can be assumed, that these elements are either totally dissolved in aluminum matrix or precipitated as dispersoids, sized below $1 \mu \mathrm{m}$.

Thus, $1565 \mathrm{ch}$ alloy as-cast structure presents solid solution of alloying elements, having limited solubility in aluminum matrix. Below the specific temperature the solution becomes supersaturated and decomposes with the second phase dispersion particles precipitation. Precipitates, occurring in the alloy (see Figure. 1, Table 3) change density and distribution pattern of the dislocations, generated during deformation, thus producing significant effect on the future recrystallization, decreasing its initiation temperature, as a rule [14]. In general, particles function as barriers for the dislocations, migrating in the matrix during deformation. It leads to local increase of dislocations density in matrix micro-volumes, adjoining the particles, growing excess of the same sign dislocations, hence increasing crystalline lattice local bending in these areas. During heating these areas become preferential zones of recrystallization nucleation. The larger the particles and the less regular shape they have, the stronger local bending is and the lower strain values are, causing such bending effect [14]. 


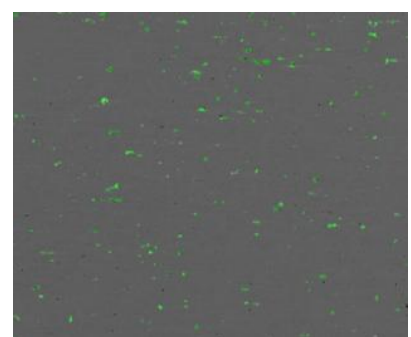

a)

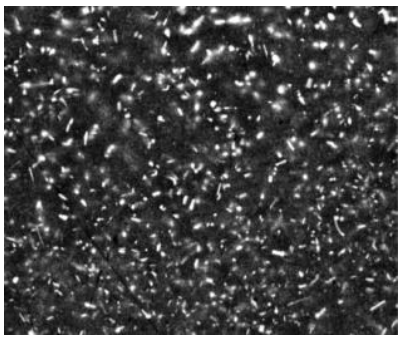

b)

Fig. 1. Cast 1565 ch alloy sample examination using scanning microscope BSED. a) x250 magnification b) x10 000 magnification

Table 3. Intermetallic particles number in $1565 \mathrm{ch}$ sample

\begin{tabular}{|c|c|c|c|}
\hline \multicolumn{4}{|c|}{$1565 \mathrm{ch}$} \\
\hline \multicolumn{3}{|c|}{$\begin{array}{c}\text { Specific fraction of } \\
\text { intermetallic particles (f), } \%\end{array}$} & Size (nominal diameter), mcm \\
\hline $\begin{array}{c}\text { Intermetallic } \\
\text { particles }\end{array}$ & Dispersoids & $\begin{array}{c}\text { Intermetallic } \\
\text { particles }\end{array}$ & Dispersoids \\
\hline 0.9341 & 13 & 6.24 & 0.148 \\
\hline
\end{tabular}

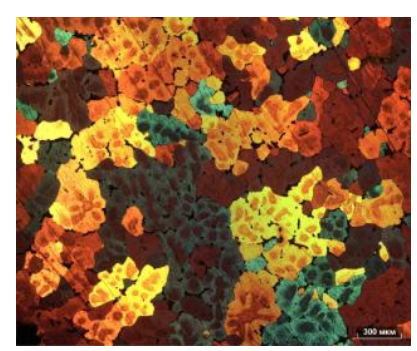

a)

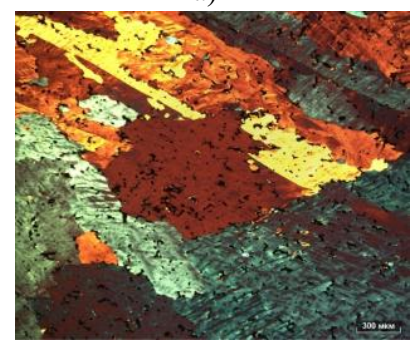

c)

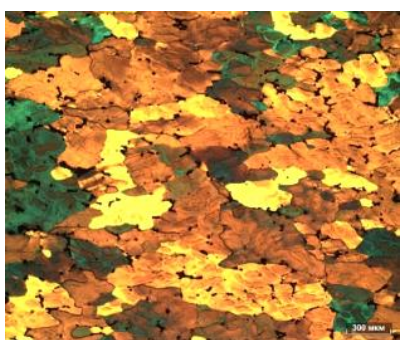

b)

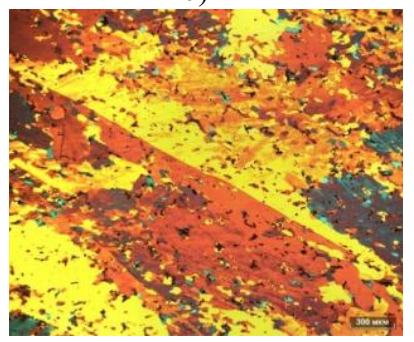

d)
Fig. 2. $1565 \mathrm{ch}$ samples examination using optical microscope: a) - cast; b) - deformed $\varepsilon=0,34 \mathrm{Z}=6.8810^{12} ; \mathrm{c}$ ) - annealed at $\left.350^{\circ} \mathrm{C}, 6 \mathrm{~min} ; \mathrm{d}\right)-$ annealed at $350{ }^{\circ} \mathrm{C}, 10 \mathrm{~min}$

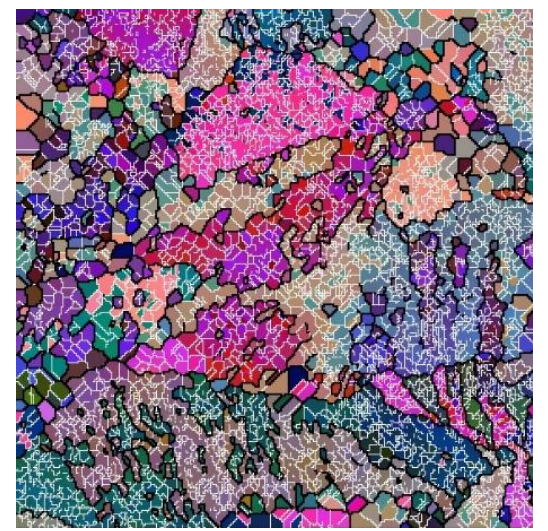

Fig. 3. Orientation analysis (EBSD). Alloy $1565, \varepsilon=0.52$; $\mathrm{Z}=5.70 \mathrm{E}+13$

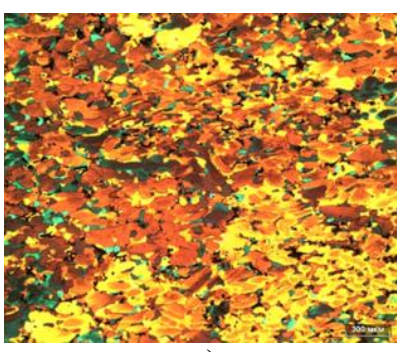

a)

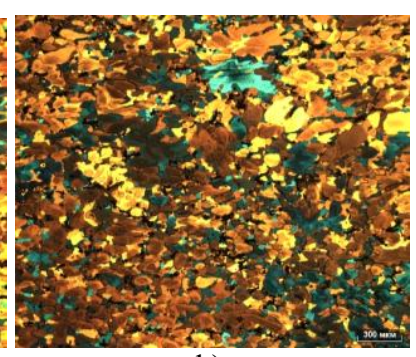

b)
Fig. 4. Optical microscope examination of alloy $1565 \mathrm{ch}$, $\varepsilon=0.52 ; Z=5.70 \mathrm{E}+13$ samples: a) annealing at $400{ }^{\circ} \mathrm{C}, 2 \mathrm{~min}$ soaking, b) annealing at $400{ }^{\circ} \mathrm{C}, 10 \mathrm{~min}$ soaking.

Dendritic structures are preserved in an ingot at about 0.5 strain degree, crystals are elongated in the rolling direction (see Figure 2b). Examination using scanning microscope with integrated EBSD tool demonstrates grain division into defined subgrains (see Figure 3). Let us analyse grain evolution at annealing temperature of $350{ }^{\circ} \mathrm{C}$, using the sample, treated at $450{ }^{\circ} \mathrm{C}$, with strain degree of 0.34 , and $3 \mathrm{~s}^{-1}$ strain rate. First recrystallization grains are observed after 6-minute soaking (see Figure 2c). Nuclei number increases after 10-minute soaking (2d).

High rate of new grains nucleation is typical during annealing at $400{ }^{\circ} \mathrm{C}$ (see Figure 4), at the same time further grain growth is significantly delayed to the extent of complete process halt, new grains shape is far from ideal hexagon, which is typical for homogenous recrystallization.

High rate of $1565 \mathrm{ch}$ alloy nucleation can be explained by PSN mechanism contribution [18]. If the heating continues after primary recrystallization nucleation, further structural modifications are associated with nuclei and grains high-angle boundaries migration. During this stage the second phase particles, represented by closely spaced fine aluminum matrix coherent particles, complicate recrystallization centres and grain boundaries migration. Particles enveloping is associated with local boundary curvature changes and boundary extension, i.e., surface energy buildup. While recrystallization centres still form at relatively low temperature, nuclei growth, as well as secondary recrystallization initiation, tend towards higher temperature. In $1565 \mathrm{ch}$ two recrystallization stages nucleation and nuclei growth - are separated by a significant temperature-time interval. $1565 \mathrm{ch}$ alloy structure has multiple dispersion particles (see Figure 1 and Table 3), presenting a barrier for grain boundaries spreading. Upon reaching such barrier, the grain boundary stops, and the grain continues growing in the direction without barrier constraints, therefore new grains have filigree boundary shape, and the structure presents the combination of as-cast dendrites with visible deformed and recrystallized structure zones. The above statement is well illustrated by the plot in Figure 5. 


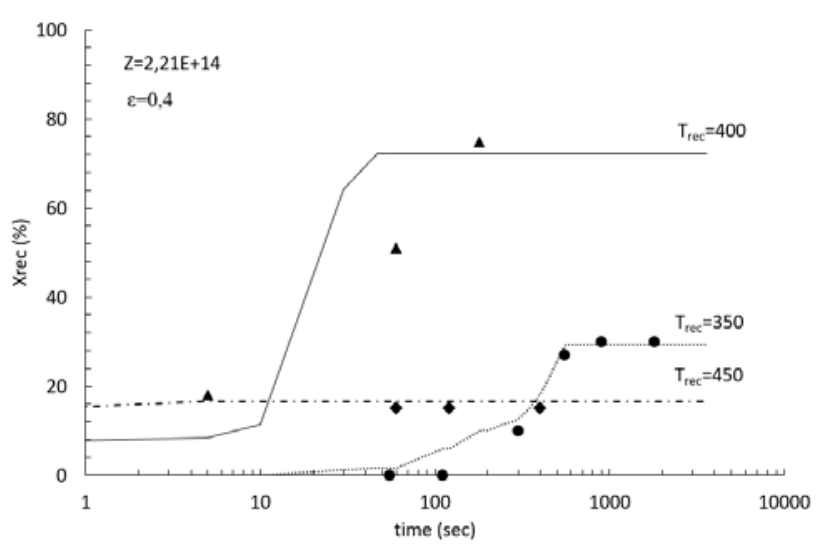

Fig. 5. 1565 ch recrystallization kinetics plot $\left(\boldsymbol{\Delta}-\mathrm{Trec}=400{ }^{\circ} \mathrm{C} ; \bullet-\operatorname{Trec}=350{ }^{\circ} \mathrm{C} ; \diamond-\operatorname{Trec}=450{ }^{\circ} \mathrm{C}\right)$

Actual data, established by the structure assessment using optical microscope, are indicated with markers, while lines indicate theoretical calculation, based on the model, presented in the previous section.

\section{Conclusions}

In the process of research plots were constructed and coefficients were computed for Johnson - Mehl Avrami - Kolmogorov type analytical equation, describing recrystallization kinetics of $1565 \mathrm{ch}$ alloy, rolled from as-cast condition using various practices with the following rolling parameters:

Temperature $300 \div 500{ }^{\circ} \mathrm{C}$;

Strain level range is $0.14 \div 0.56$;

Strain rates are 3 and $8 \mathrm{~s}^{-1}$;

Initial workpiece grain size is $200 \mathrm{mcm}$.

The obtained data allow the conclusion, that $1565 \mathrm{ch}$ alloy recrystallization process with low degree of as-cast structure deformation $(0.14 \div 0.56)$ is characterized by a number of specific features, such as high rate of new grains nucleation and low rate of grains growth to the extent of such process total blocking. Optimal recrystallization temperature is established $-400{ }^{\circ} \mathrm{C}$, it enables over $75 \%$ process progression, incubation period increases in case of temperature decrease $\left(350{ }^{\circ} \mathrm{C}\right)$, and recrystallization halts, producing about $30 \%$ estimated volume of recrystallized structure, in case of temperature rise $\left(450{ }^{\circ} \mathrm{C}\right)$ the structure is saturated with small new grains nuclei, probably, formed during heating, but due to high recovery and polygonization intensity, recrystallization driving force is reduced to zero, the process terminates, producing combined structure with $\max 20 \%$ recrystallized grains volume.

\section{References}

1. J. Hirsch, Fundamentals of Aluminium Metallurgy, 1 (2011)
2. J. Hirsch, Light Metals warrendale proceedings, $\mathbf{5}$ (2008)

3. C. Schäfer, V. Mohles, G. Gottstein, Applications of Texture Analysis, 1 (2008)

4. O. Engler, L. Löchte, K. F. Karhausen, Materials Science Forum, 495 (2005)

5. O. Engler, Materials science forum, $\mathbf{5 5 0}$ (2007)

6. O. Engler, H. E. Vatne, JOM. 50, 6 (1998)

7. J. Hirsch, Materials Science Forum, 702 (2012)

8. M. A. Golovnin, R. F. Iskhakov, III International Scientific School for Young Scientists "Material Science and Physics of Light Metals", (2014)

9. V. K. Orlov, V. G. Drozd, M. A. Sarafanov, Journal Proizvodstvo Prokata, 4 (2016)

10. E. V. Aryshenskii, M. S. Tepterev, I. A. Latushkin Electrical Engineering. Power Industry. Machine Building, 1 (2014)

11. V.V. Yashin, V.Yu. Aryshensky, I.A. Latushkin, M.S. Tepterev, Non-ferrous Metals Journal, 7 (2018)

12. H. Zhang, D. S. Peng, L. B. Yang, L. P. Meng, Trans Nonferrous Met Soc China, 11, 3 (2001)

13. M. A. Wells, I. V. Samarasekera, J. K. Brimacombe, E. B. Hawbolt, D. J. Lloyd, Metallurgical and Materials Transactions B, 29, 3 (1998)

14. S.S. Gorelik, S.V. Dobatkin, L.M. Kaputkina Recrystallization of metals and alloys, (2005)

15. B. Koohbor, International journal of material forming, 7, 1 (2014)

16. A. Nam, V. Yashin, E. Aryshenskii, A. Zinoviev, R. Kawalla, Materials Science Forum. - Trans Tech Publications, 918 (2018)

17. E.V. Aryshenskii, A.F. Grechnikova, V.V. Yashin, Electrical Engineering. Power Industry. Machine Building, 1 (2014)

18. F. J. Humphreys, M. Hatherly, Recrystallization and related annealing phenomena, (2012)

19. O. Dalland, E. Nes, Acta materialia, 444 (1996)

20. H. E. Vatne, E. Nes, O. Daaland, Materials science forum, 157 (1994)

21. H. E. Vatne, E. Nes, Scripta Metallurgica et Materialia, 30, 3 (1994)

22. M. Avrami, The Journal of chemical physics, 712 (1939)

23. A.Yu. Churyumov Aluminum alloys ultimate yield strength and deformation hardening computation using structure parameters. Extended abstract of Ph.D (Engineering) Dissertation. Moscow. 2008. 